\title{
Anthropometry of fetal growth in rural Malawi in relation to maternal malaria and HIV status
}

\author{
B F Kalanda, S van Buuren, F H Verhoeff, B J Brabin
}

Arch Dis Child Fetal Neonatal Ed 2005;90:F161-F165. doi: 10.1136/adc.2004.054650

See end of article for authors' affiliations

.....................

Correspondence to: Professor Brabin, Child and Reproductive Health Group, Liverpool School of Tropical Medicine,

Pembroke Place, Liverpool L3 5QA, UK; b.j.brabin@ liv.ac.uk

Accepted

27 September 2004

\begin{abstract}
Objective: To describe fetal growth centiles in relation to maternal malaria and HIV status, using cross sectional measurements at birth.

Design: A cross sectional study of pregnant women and their babies. Data on maternal socioeconomic status and current pregnancy, including HIV status and newborn anthropometry, were collected. Malaria parasitaemia was assessed in maternal peripheral and placental blood, fetal haemoglobin was measured in cord blood, and maternal HIV status was determined.

Setting: Two district hospitals in rural southern Malawi, between March 1993 and July 1994.

Outcome variables: Newborn weight, length, Rohrer's ponderal index.

Results: Maternal HIV (adjusted odds ratio (AOR) 1.76 (95\% confidence interval 1.04 to 2.98)) and first pregnancy (AOR 1.83 (1.10 to 3.05)) were independently associated with low weight for age. Placental or peripheral parasitaemia at delivery (AOR 1.73 (1.02 to 2.88)) and primigravidae (AOR 2.13 (1.27 to 3.59)) were independently associated with low length for age. Maternal malaria at delivery and primiparity were associated with reduced newborn weight and length but not with disproportionate growth. Maternal HIV infection was associated only with reduced birth weight. The malaria and parity effect occurred throughout gestational weeks 30-40, but the HIV effect primarily after 38 weeks gestation. Conclusion: Fetal growth retardation in weight and length commonly occurs in this highly malarious area and is present from 30 weeks gestation. A maternal HIV effect on fetal weight occurred after 38 weeks gestation.
\end{abstract}

A ttained size at birth is an agreed clinical measure for analysing and monitoring prenatal events and outcome. ${ }^{1}$ Assessment of unusual patterns of intrauterine growth is therefore an important element of obstetric and prenatal care. Intrauterine growth is one of the most vulnerable periods in the human life cycle, with growth retardation having profound influence on subsequent health. ${ }^{2}$ Growth retardation is directly associated with poor neonatal outcomes, including infant mortality ${ }^{3-5}$ which can be mediated mainly through low birth weight. ${ }^{6}$ It may be linked to several poor health conditions in later adult life, although the evidence for this has been questioned. ${ }^{8}$

Causal factors that predispose to poor fetal growth include maternal nutrition, impaired placental function, maternal diseases, infections, and environment influences. ${ }^{90}$ An analysis of the present Malawian data set has previously assessed birth weight for gestational age distribution in relation to maternal health and nutritional status. ${ }^{11}$ The aim of the present analysis was to describe fetal growth centiles, using cross sectional measurements at birth, in relation to maternal malaria and HIV infection. A further aim was to examine factors associated with growth restriction in weight and length in newborn babies born in a highly malarious area of rural Malawi.

\section{METHODS}

\section{Study area}

This study was undertaken between March 1993 and July 1994 in Chikwawa District, Shire Valley, southern Malawi. This rural area with endemic malaria transmission covers about $4800 \mathrm{~km}^{2}$ and is $10-300 \mathrm{~m}$ above sea level. Average rainfall in the study period was $520 \mathrm{~mm} /$ year mostly falling in November-March. ${ }^{12}$ Small scale agriculture of maize, sorghum, cotton, and sugar cane are the primary sources of food and income. Estimated population size in 1998 was
356 682, of which 77701 were women of child bearing age. ${ }^{13}$ The study was located in Chikwawa District Hospital, a government hospital with free services, and Montfort Hospital, $30 \mathrm{~km}$ away, a fee paying mission hospital.

\section{Enrolment}

All women attending the antenatal facilities at the two hospitals were screened at their first antenatal visit after verbal consent had been obtained. A questionnaire, completed by a project nurse, included information on age, obstetric history, and antimalarial use in pregnancy. Literacy status was assessed from the reading of a simple sentence in the local language.

\section{Delivery}

It was not possible to obtain delivery information from home or health centre deliveries. Birth weight was measured on a Salter scale (nearest $10 \mathrm{~g}$ ), and the baby was examined at 6-24 hours for gestational age using a modified Ballard method. ${ }^{14}$ Birth length was measured (nearest $0.1 \mathrm{~cm}$ ) with the baby supine using a standardised measuring mat. Head circumference (occipitofrontal) was measured by tape $(\mathrm{mm})$ (Talc, Guildford, Surrey, UK), and so was the circumference at the mid-point of the left upper arm. A blood sample was collected at delivery by venepuncture from the mother and umbilical cord. A malaria slide was made from blood collected deep between the placenta villi. These were stained with Giemsa and read counting asexual Plasmodium falciparum parasites against 200 white blood cells. Maternal HIV status was determined using two different enzyme linked immunosorbent assays: ICE*HIV-1.0.2 (Murex, Dartford, Kent, UK) and, for confirmation, VIDAS HIV-2 new test (bioMerieux, Lyon, France). This procedure was in accordance with WHO recommendations for HIV diagnosis in asymptomatic patients from regions with prevalence above 
Table 1 Mean anthropometric values in relation to maternal malaria (peripheral or placental parasitaemia)

\begin{tabular}{|c|c|c|c|c|c|}
\hline \multirow[b]{2}{*}{ Index } & \multicolumn{2}{|c|}{ Parasitaemia +ve } & \multicolumn{2}{|c|}{ Parasitaemia -ve } & \multirow[b]{2}{*}{ p Value } \\
\hline & $\mathbf{n}$ & Mean (SD) & $\mathbf{n}$ & Mean (SD) & \\
\hline Birth weight (g) & 361 & $2843(533)$ & 983 & $2960(450)$ & 0.001 \\
\hline Birth length $(\mathrm{cm})$ & 353 & $47.1(2.7)$ & 971 & $47.7(2.3)$ & 0.001 \\
\hline Head circumference $(\mathrm{cm})$ & 355 & $33.4(1.7)$ & 977 & 33. $8(1.5)$ & 0.001 \\
\hline $\mathrm{PI}\left(\mathrm{kg} / \mathrm{cm}^{3}\right)$ & 353 & $27.5(7.2)$ & 970 & $27.5(6.3)$ & 0.87 \\
\hline
\end{tabular}

$10 \%{ }^{15}$ Counselling was provided by trained nurses before and after the test. A subsample of sera, selected randomly $(\mathrm{n}=$ 651), was tested for HIV.

\section{Definitions}

Cord haemoglobin of less than $125 \mathrm{~g} / \mathrm{l}$ defined fetal anaemia. ${ }^{16}$ Adolescence was defined as $12-19$ years of age. Malaria at delivery was present if the mother had placental malaria and/or peripheral parasitaemia. Babies less than 37 weeks at delivery were preterm and less than $2500 \mathrm{~g}$ low birth weight. Wasting (low weight for age (W/A)), thinness (low weight for length $(\mathrm{W} / \mathrm{L}))$ and stunting (low length for age $(\mathrm{L} / \mathrm{A})$ ) were defined as a standard deviation score of less than or equal to $-2.0 .{ }^{17}$ Rohrer's ponderal index was computed as birth weight $(\mathrm{g}) /$ birth length $^{3}(\mathrm{~cm}) \cdot{ }^{18}$

\section{Analysis}

Data were analysed using SPSS for windows, version 11.0 (2001). The $\chi^{2}$ and Fisher's exact tests were used for comparison of discrete variables, and analysis of variance for continuous variables. Logistic regression was used to analyse risk factors related to wasting, stunting, and thinness. For adjusted odds ratios (AORs), p $<0.05$ was taken as significant. Growth curves were drawn using smoothed centile standards derived by the LMS program, ${ }^{19}$ version 1.16 (2000). The LMS method assumes that the data can be normalised by using a power transformation, which stretches one tail of the distribution and shrinks the other to remove skewness. The optimal power to obtain normality depends on age and is summarised by a smooth age dependent $\mathrm{L}$ curve. Trends in the median (M) and coefficient of variation (S) are similarly smoothed. Curve smoothness was decided by varying the $\mathrm{L}, \mathrm{M}$, and $\mathrm{S}$ values and observing the detrended Q-Q plots. Standard deviation scores were calculated using

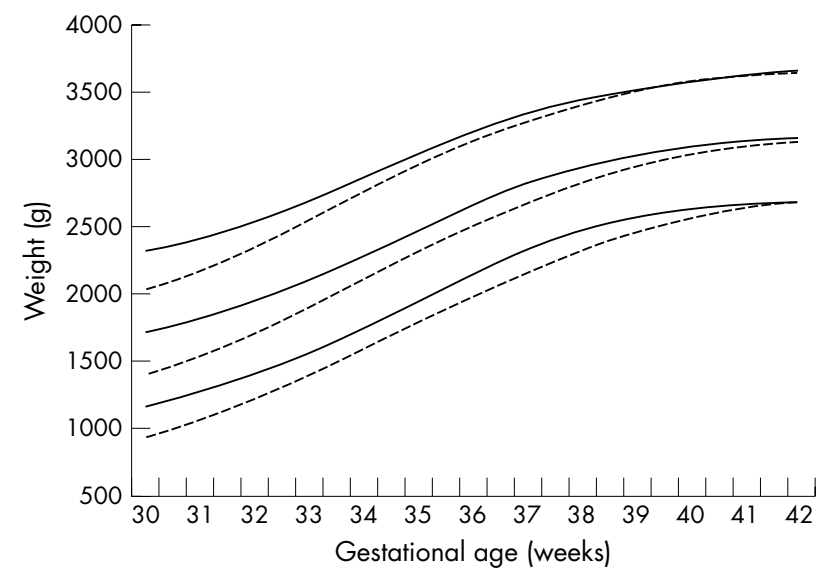

Figure 1 Birth weight for gestational age centiles (10th, 50th, 90th) in relation to maternal malaria. Broken line, positive for malaria parasites in peripheral or placental blood; continuous line, negative for parasites.

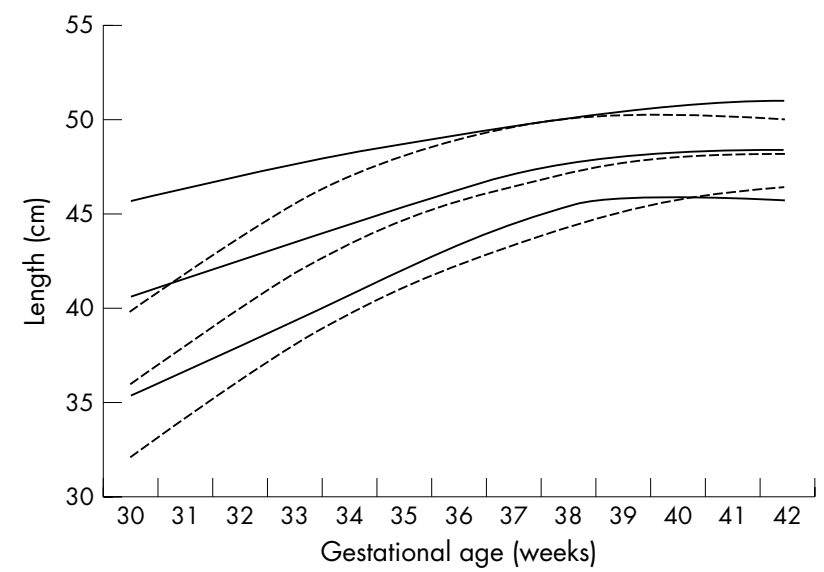

Figure 2 Birth length for gestational age centiles (10th, 50th, 90th) in relation to maternal malaria at delivery. Broken line, positive for malaria parasites in peripheral or placental blood; continuous line, negative for parasites.

the EPI info 2002, nutrition program, using the CDC 2000 reference as the standards. ${ }^{20}$ Twins and stillbirths were excluded from the analysis.

\section{Ethical approval}

The study was granted ethical approval by the College of Medicine Research and Ethics Committee.

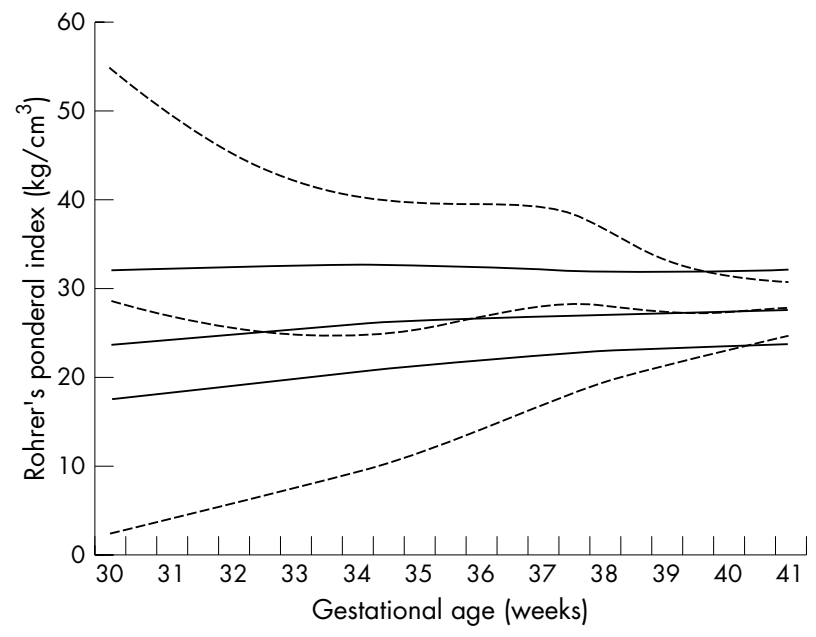

Figure 3 Rohrer's ponderal index centiles (10th, 50th, 90th) by gestational age in relation to maternal malaria at delivery. Broken line, positive for malaria parasites in peripheral or placental blood; continuous line, negative for parasites. 


\section{RESULTS}

A total of 4104 pregnant mothers were recruited at antenatal clinics. Of these, 1571 (38\%) delivered in the study hospitals. There were 86 twins and 55 stillbirths. Four twins were stillborn, and for three infants there was missing information. These were excluded, leaving 1423 infants for the analysis. Of these, $49.7 \%$ (707) were male, $21.7 \%$ (309) had fetal anaemia, $17.1 \%$ (243) were preterm, and 14.8\% (211) were low birth weight. Details of the gestation age distribution in this sample have been previously published. ${ }^{21}$ Of the mothers, $24.3 \%$ (344) were primigravidae, $22.4 \%$ (248) adolescent, and $26.9 \%$ (362) had placental or peripheral parasitaemia at delivery. From a sample of 621 screened for HIV, 25.6\% were positive for HIV antibody.

Table 1 shows anthropometric indices for infants of mothers with and without malaria at delivery. Birth weight, length, and head circumference were significantly reduced if mothers were parasitaemic at delivery. Figures $1-3$ present the centile curves for the same variables stratified by the presence or absence of malaria parasitaemia. Centile values for both weight and length were consistently lower in babies of parasitaemic compared with non-parasitaemic mothers. The 50th centile ponderal index of babies did not differ by maternal malaria status, indicating that growth was proportionate (fig 3). Gestational age did not differ by maternal malaria status (38.4 $v 38.6$ weeks, $\mathrm{p}=0.07$ ).

Figure 4 presents the centile curves for birth weight for primigravidae and multigravidae separately. Mean birth weight was lower $(p<0.001)$ at all gestational ages in infants of primigravidae. Similarly birth length, head circumference, and mid-upper arm circumference were lower at all gestational ages in infants of primigravidae (data not shown). Figure 5 presents birth weight centile curves in relation to maternal HIV status. There was little difference between growth patterns of babies born to HIV positive or negative mothers, before 38 weeks gestation, although the fall off in centiles after 38 weeks in babies of HIV positive mothers was significant $(p<0.05)$. Centiles also did not differ between babies with or without fetal anaemia $(p>0.1$ ) (data not shown).

Mean z scores for W/A and L/A were significantly different between babies of adolescents and non-adolescents, between primigravidae and multigravidae, and in relation to placental or peripheral parasitaemia at delivery (table 2). Differences in anthropometric indices in relation to the infant's sex were consistent for different maternal characteristics, except for maternal HIV status. This showed that female infants of HIV positive mothers were likely to be lighter $(p=0.055)$ and

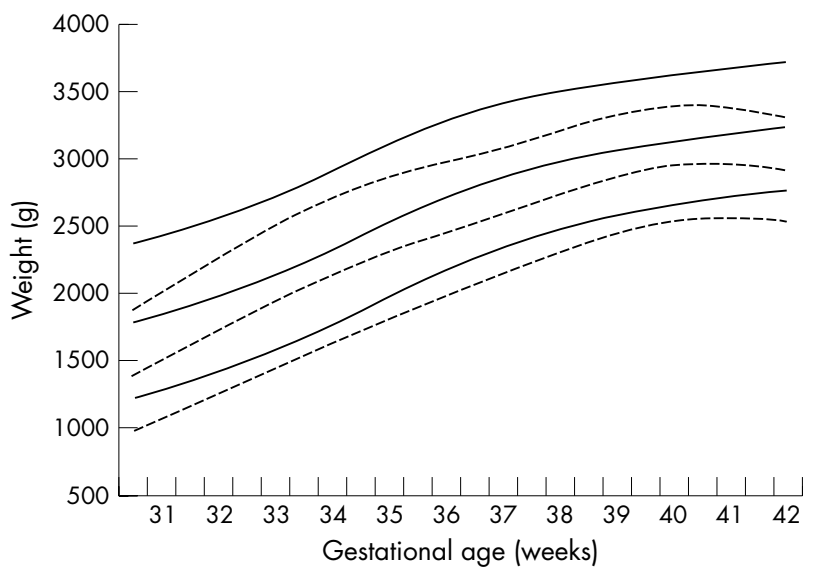

Figure 4 Birth weight for gestational age centiles (10th, 50th, 90th) for primigravidae (broken line) and multigravidae (continuous line).

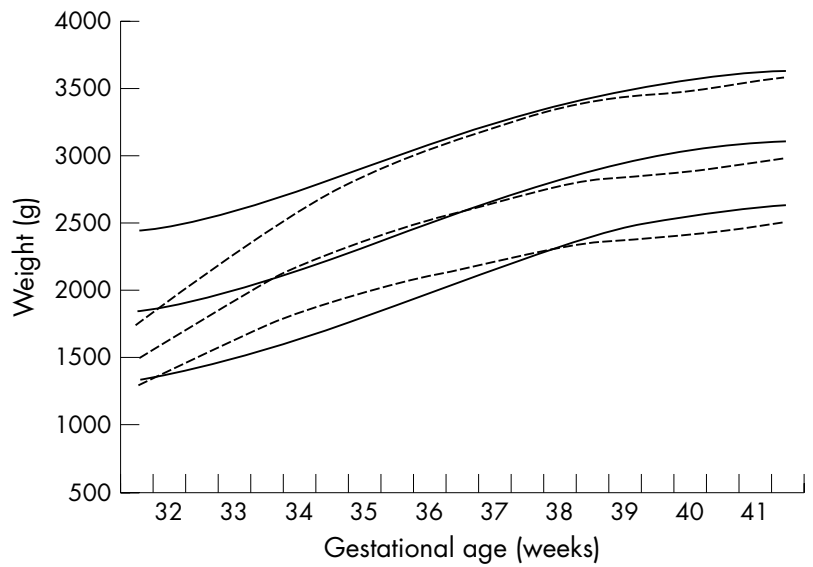

Figure 5 Birth weight for gestational age centiles (10th, 50th, 90th) for HIV positive (broken line) and negative mothers (continuous line).

shorter $(\mathrm{p}=0.095)$. Although the effects are not statistically significant, there is a trend that girls born of HIV positive mothers are lighter and shorter.

Univariate analysis showed placental and/or peripheral malaria at delivery was associated with low W/A and L/A, but not with low W/L. Maternal HIV infection was associated with low W/A but not low L/A. Primigravidae adolescence and fetal anaemia were associated with low W/A and L/A.

The following risk factors were included in the multivariate analysis: infant sex, fetal anaemia, adolescent status, parity, maternal malaria and HIV status, and gestational age. In this analysis maternal HIV infection (AOR 1.76 (95\% confidence interval 1.04 to 2.98 )) and primigravidae (AOR 1.83 ( 1.10 to 3.05)) were associated with low W/A controlling for the covariates. Placental or peripheral parasitaemia at delivery (AOR 1.73 (1.02 to 2.88)) and primigravidae (AOR 2.13 (1.27 to 3.59)) were independently associated with reduced L/A.

\section{DISCUSSION}

Mean birth weight and length were significantly lower in babies of mothers with delivery malaria. This reduction is probably associated with placental insufficiency resulting from malaria, which leads to intrauterine growth restriction. ${ }^{22}{ }^{23}$ This is illustrated in fig 1 , which shows that the mean birth weights of babies born to mothers with malaria at delivery were lower across all gestational ages. Malarial lesions probably lead to inadequate uteroplacental ${ }^{24}$ and umbilical blood flow, and alterations in the transplacental transfer of glucose or production of fetal insulin. Placental lactogen, somatomedin, and somatostatin-like substances, which influence fetal growth, may be affected. ${ }^{25}{ }^{26}$ Disturbed placental folate metabolism may be important. ${ }^{27}$ Gestational age did not differ significantly between mothers with or without delivery malaria. This suggests that, in this population, malaria was associated with low birth weight primarily through growth restriction, leading to proportionate fetal growth retardation. This is supported by the similarity of the ponderal index centiles for babies of mothers with and without malaria at delivery (fig 3 ) and by the univariate analysis, as malaria at delivery was independently associated with low W/A and L/A but not with low W/L (table 2).

Mean birth weight and length were significantly lower from about 30 weeks gestation in babies whose mothers were primigravidae. Although it is universally recognised that the mean birth weights of primigravidae are lower, ${ }^{28-30}$ far less has been reported on the association between parity and other anthropometric measurements. Parity differences have been considered to be enhanced by greater efficiency 
Table 2 Newborn z scores for different maternal study characteristics

\begin{tabular}{|c|c|c|c|c|c|c|c|c|c|c|}
\hline \multirow[b]{3}{*}{ Index } & \multicolumn{4}{|c|}{ Adolescents } & \multicolumn{4}{|c|}{ Non-adolescents } & \multirow{2}{*}{\multicolumn{2}{|c|}{ p Value }} \\
\hline & \multicolumn{2}{|c|}{ Number } & \multicolumn{2}{|l|}{ z Score } & \multicolumn{2}{|c|}{ Number } & \multicolumn{2}{|l|}{ z Score } & & \\
\hline & Male & Female & Male & Female & Male & Female & Male & Female & Male & Female \\
\hline$W / L$ & 112 & 89 & $-0.03(1.1)$ & $-0.05(0.9)$ & 375 & 404 & $0.28(0.9)$ & $0.20(0.9)$ & 0.003 & 0.018 \\
\hline W/A & 136 & 109 & $-1.24(0.8)$ & $-1.31(0.8)$ & 404 & 447 & $-0.84(0.7)$ & $-0.90(0.8)$ & $<0.001$ & 0.000 \\
\hline \multirow{2}{*}{ L/A } & 132 & 106 & $-1.03(0.9)$ & $-1.08(1.0)$ & 399 & 444 & -0.7610 .7 & $-0.77(0.9)$ & $<0.001$ & 0.002 \\
\hline & \multicolumn{4}{|c|}{ Primigravidae } & \multicolumn{4}{|c|}{ Multigravidae } & & \\
\hline$W / L$ & 133 & 143 & $-0.06(1.0)$ & $-0.01(0.9)$ & 491 & 480 & $0.30(0.9)$ & $0.22(0.9)$ & $<0.001$ & 0.012 \\
\hline W/A & 168 & 172 & $-1.32(0.7)$ & $-1.29(0.8)$ & 532 & 534 & $-0.79(0.7)$ & $-0.86(0.8)$ & $<0.001$ & 0.000 \\
\hline \multirow[t]{2}{*}{ L/A } & 163 & 168 & $-1.12(0.9)$ & $-1.11(1.0)$ & 525 & 525 & $-0.72(0.7)$ & $-0.74(0.9)$ & $<0.001$ & 0.000 \\
\hline & \multicolumn{4}{|c|}{ Placental/peripheral malaria } & \multicolumn{6}{|c|}{ No placental/peripheral malaria } \\
\hline $\mathrm{W} / \mathrm{L}$ & 146 & 145 & $0.15(1.0)$ & $0.17(0.9)$ & 454 & 440 & $0.25(0.9)$ & $0.17(0.9)$ & 0.235 & 0.985 \\
\hline W/A & 178 & 181 & $-1.03(0.8)$ & $-1.14(0.9)$ & 494 & 484 & $-0.88(0.7)$ & $-0.91(0.8)$ & 0.029 & 0.002 \\
\hline L/A & \multicolumn{4}{|c|}{ HIV positive } & \multicolumn{2}{|c|}{ HIV negative } & $-0.78(0.8)$ & $-0.77(0.9)$ & 0.012 & 0.002 \\
\hline $\mathrm{W} / \mathrm{L}$ & 64 & 61 & $0.08(0.9)$ & $0.03(1.0)$ & 185 & 188 & $0.17(1.0)$ & $0.11(0.9)$ & 0.529 & 0.522 \\
\hline W/A & 73 & 81 & $-1.14(0.7)$ & $-1.30(0.9)$ & 220 & 222 & $-1.04(0.8)$ & $-1.09(0.8)$ & 0.314 & 0.055 \\
\hline $\mathrm{L} / \mathrm{A}$ & 73 & 78 & $-0.98(0.7)$ & $-1.20(1.1)$ & 217 & 221 & $-0.95(0.9)$ & $-1.0(1.0)$ & 0.778 & 0.095 \\
\hline
\end{tabular}

of the uterine circulation in second and subsequent pregnancies. ${ }^{31}$ However, in malarious areas, primigravidae have a much higher incidence of falciparum malaria than multigravidae, ${ }^{32} 33$ and this exposure must increase the magnitude of the normal parity difference observed for fetal size between parity groups as has been reported in this population. ${ }^{34}$ Fetal size for all newborn anthropometric variables for this population, including head and arm circumference, is considerably below that of a Swedish reference population (unpublished work).

Anthropometric measurements did not differ significantly between babies with or without fetal anaemia. In Brazil, Rondo and Tomkins ${ }^{35}$ assessed the effects of fetal anaemia on intrauterine growth restriction and also found no significant association between fetal anaemia and growth restriction (OR 0.66 (95\% confidence interval 0.46 to 0.95$)$ ). We have previously reported no significant association between fetal growth restriction and fetal anaemia in this Malawian population. $^{36}$

Mean birth length, head circumference, and mid-upper arm circumference did not differ significantly between babies of HIV positive and HIV negative mothers. This has also been reported by Moye $e a^{37}$ in a multicentre study from mainland United States and Puerto Rico. A study in Butare, Rwanda reported reduced birth length and head circumference $(\mathrm{p}<0.01)$ in babies born to HIV positive mothers. ${ }^{38}$ In another study in Kigali, Rwanda, Leroy et $a^{39}$ observed reduced birth length and head circumference $(\mathrm{p}<0.001)$ in babies of HIV positive mothers. In the Rwandan study, it was reported that HIV reduced body mass index and the weight to head ratio, which led to speculation on HIV causing disproportionate intrauterine growth restriction. No association of HIV with the ponderal index was observed in the present study, suggesting that maternal HIV infection does not cause disproportionate growth.

These published studies confirm the reduced birth weight of babies of HIV positive mothers. In this study, this was marginally significant (W/A) only for female infants $(p=$ 0.055). This confirms results in the European Collaborative study where girls were at 1.5 increased risk of mother to child HIV transmission..$^{40}$ The sex effect was limited to elective caesarean section, suggesting that girls may have an increased risk of intrauterine transmission compared with boys. Similar sex differences in mother to child transmission have been reported among Malawian newborns. ${ }^{41}$ Analysed for both sexes combined, birth weight $(\mathrm{p}=0.04)$ and W/A $(\mathrm{p}=0.03)$ differed significantly according to maternal HIV status, and this was more apparent from 38 weeks gestation. This may indicate that mother to child transmission of HIV primarily occurs in late gestation.

\section{CONCLUSIONS}

In this area of Malawi, chronic fetal growth restriction occurred primarily due to falciparum malaria and resulted in proportionate changes in fetal weight and length. HIV infection may have a late gestational effect on fetal size. To improve fetal growth in developing countries, health interventions should prioritise malaria control in pregnancy, as well as preventing mother to child transmission of HIV.

\section{ACKNOWLEDGEMENTS}

We are grateful for support received from staff at Chikwawa and Montfort Hospitals and to B Makwisa, S Mlanga, V Nakoma, M Gwaza, and $\mathrm{H}$ Banda and to laboratory technicians for technical support. Financial support was provided by the Gates Malaria Partnership (BFK) and the European Commission Programme for Life Sciences and Technologies for Developing Countries (Contract TS3* $^{*}$ CT 920083).

\section{Authors' affiliations}

B F Kalanda, F H Verhoeff, B J Brabin, Child and Reproductive Health Group, Liverpool School of Tropical Medicine, Liverpool, UK

B F Kalanda, College of Medicine, University of Malawi, Blantyre, Malawi

S van Buuren, Department of Statistics, TNO Prevention and Health, Leiden, the Netherlands

B J Brabin, Academic Medical Centre, University of Amsterdam, the Netherlands

Competing interests: none declared

\section{REFERENCES}

1 Dunn PM. The search for perinatal definitions and standards. Acta Paediatr Scand 1985;319(suppl):7-16.

2 Guemezoglu M, de Onis M, Villar J. Effectiveness of interventions to prevent or treat impaired fetal growth. Obstet Gynecol Survey 1997;52:139-49.

3 Chu PW, Ecker JL, Feldstein VA, et al. US Evaluation of fetal growth: prediction of neonatal outcomes. Radiology 2002;223:153-61.

4 Mclntire DD, Bloom SL, Casey BM, et al. Birthweight in relation to morbidity and mortality among new born infants. N Engl J Med 1999;340:1234-8.

5 Villar J, de Onis M, Kestler E, et al. The differential morbidity of the intrauterine growth retardation syndrome. Am J Obstet Gynecol 1990;163:151-7. 
6 Forssa $E$, Gissler M, Sihvonen $M$, et al. Maternal predictors of perinatal mortality: the role of birthweight. Int J Epidemiol 1999;28:475-8.

7 de Onis M, Villar J, Gulmezoglu M. Nutritional interventions to prevent intrauterine growth retardation: evidence from randomized controlled trials. Eur J Clin Nutr 1998:52(suppl 1):S83-93.

8 Williams S, St George IM, Silva PA. Intrauterine growth retardation and blood pressure at age seven and eighteen. J Clin Epidemiol 1992;45:1257-63.

9 Abdul-Karim RW, Beydoun SN. Growth of the human fetus. Clin Obstet Gynecol 1974:17:37.

10 Babson GS, Behrman RE, Lessel R. Liveborn birthweights for gestational age of white middle class infants. Pediatrics 1970;45:937-44.

11 Verhoeff FH, Brabin BJ, van Buuren S, et al. An analysis of intra-uterine growth retardation in rural Malawi. Eur J Clin Nutr 2001;55:682-9.

12 Sugar Co-operation of Malawi (SUCOM). Meteorological data, 1993-1994. Nchalo, 1995.

13 National Statistical Office (NSO). Malawi population and housing census. Summary of final results, volume 1, Zomba, Malawi, 1998.

14 Verhoeff FH, Milligan P, Brabin BJ, et al. Gestational age assessment by nurses in a developing country using the Ballard method, external criteria only. Ann Trop Paediatr 1997; 17:333-42.

15 World Health Organisation. Global programme on AIDS: recommendation for the selection and use of HIV antibody tests. Weekly Epidemiology Review 1992:20:145-9.

16 Brabin BJ. Fetal anaemia in malarious areas: its causes and significance. Ann Trop Paediatr 1992;12:303-10.

17 Waterlow JC, Buzina R, Keller W, et al. The presentation and use of height and weight data for comparing the nutritional status of groups of children under the age of 10 year. Bull World Health Organ 1977:55:489-98.

18 World Health Organisation. Physical status: the use and interpretation of anthropometry. Geneva: WHO, 1995

19 Cole TJ, Freeman JV, Preece MA. British 1990 growth reference centiles for weight, height, body mass index and head circumference fitted by maximum penalized likelihood. Stat Med 1998;17:407-29.

20 Ogden C, Kuczmarski RJ, Flegal KM, et al. Centers for Disease Control and Prevention 2000 growth charts for the United States: improvements to the 1977 National. Center for Health Statistics version. Pediatrics 2002; 109:45-60

21 Verhoeff FH, Brabin BJ, van Burren S, et al. An analysis of intra-uterine growth retardation in rural Malawi. Eur J Clin Nutr 2001;55:682-69.

22 Meuris S, Piko BB, Eerens P, et al. Gestational malaria: assessment of its consequences on fetal growth. Am J Trop Med Hyg 1993;48:603-9.

23 Menendez C, Ordi J, Ismail MR, et al. The impact of placental malaria on gestational age and birthweight. $J$ Infect Dis 2000;181:1740-5.
24 Brabin BJ, Romagosa C, Abdelgalil S, et al. The sick placenta: the role of malaria. Placenta 2004;25:359-78.

25 Falkner F. Key issues in perinatal growth. Acta Paediatr Scand 1985;319(suppl):21-5.

26 Vorherr H. Factors influencing fetal growth. Am J Obstet Gynecol 1982; 12:577-88.

27 Brabin BJ, Fletcher KA, Brown N. Do disturbances within the folate pathway contribute to low birthweight in malaria? Trends Parasitol 2003;19:39-43.

28 Gardosi J, Mongelli $M$, Wilcox $M$, et al. An adjustable fetal weight standard. Ultrasound Obstet Gynecol 1995;6:168-74.

29 Goldenberg RL, Cutter GR, Hoffman HJ, et al. Intrauterine growth retardation. Standards for Diagnosis 1989:161:271-77.

30 Milner RDG, Richards B. An analysis of birthweight by gestational age of infants born in England and Wales, 1967-1971. J Obstet Gynaecol Br Commonw 1974;81:956-67.

31 Thomson AM, Billewicz WZ, Hytten FE. The assessment of fetal growth J Obstet Gynaecol Br Commonw 1968;75:903-16.

32 Brabin BJ. An analysis of malaria in pregnancy in Africa. Bull World Health Organ 1983;61:1005-16.

33 McGregor IA. Epidemiology, malaria and pregnancy. Am J Trop Med Hyg 1984;33:517-25

34 Vehoeff FH, Brabin BJ, Chimsuku L, et al. An evaluation of the effects of intermittent sulphadoxine treatment in pregnancy on parsite clearance and risk of low birthweight in rural Malawi. Ann Trop Med Parasitol 1998:92:141-50.

35 Rondo PHC, Tomkins AM. Maternal iron status and intrauterine growth retardation. Trans R Soc Trop Med Hyg 1999;93:423-6.

36 Brabin BJ, Kalanda BF, Verhoeff FH, et al. Risk factors for fetal anaemia in a malarious area of Malawi. Ann Trop Paediatr 2004; in press.

37 Moye J, Rich KC, Kalish LA, et al. Natural history of somatic growth in infants born to women infected by human immunodeficiency virus. J Pediatr 1996; 128:58-69.

38 Bulterys M, Chao A, Munyemana S, et al. Maternal human immunodeficiency virus 1 infection and intrauterine growth retardation: a prospective cohort study in Butare, Rwanda. Pediatr Infect Dis J 1984;13:94-100.

39 Leroy $\mathbf{V}$, Ladner J, Nyiraziraje $M$, et al. Effect of HIV-1 infection on pregnancy outcome in women in Kigali, Rwanda, 1992-1994. AIDS 1998;12:643-50.

40 Thorne C, Newell M-L. Are girls more at risk of intrauterine-acquired HIV infection than boys. European Collaborative Study. AIDS 2004; 18:344-7.

41 Taha TE, Nour S, Kumwenda NI, et al. Gender differences in perinatal HIV acquisition among African infants [abstract]. XV International AIDS Conference, Bangkok, Thailand, July 12-16, 2004; Abstract Th Or C1420". 